\title{
Population structure and dynamics of insecticide resistance genes in Culex pipiens populations from Italy
}

\author{
FRANCESCO SILVESTRINI*†, CARLO SEVERINI†, VALERIA DI PARDO $\dagger$, ROBERTO \\ ROMI†, ELVIRA DE MATTHAEIS \& \& MICHEL RAYMOND§ \\ †Laboratorio di Parassitologia, Istituto Superiore di Sanità, Viale Regina Elena 299, 00161 Rome, Italy, \$Dipartimento \\ BAU, Università di Roma 'La Sapienza', Viale dell'Università 32, 00185 Rome, Italy and §Laboratoire Génétique et \\ Environnement, Institut des Sciences de I'Evolution (ISEM No. 98071), Université de Montpellier II, Place E. \\ Bataillon, 34095 Montpellier, France
}

\begin{abstract}
We have studied the distribution of resistance genes in relation to genetic structure and gene flow between field populations of Culex pipiens from Italy. Electrophoretic polymorphism of 12 supposed neutral genes showed that genetic differentiation among samples was low and indirect values of $\mathrm{Nm}$ provided high estimates of gene flow. In contrast, we observed a strong differentiation in the distribution of resistance genes, highly correlated with the presence/ absence of organophosphate insecticide treatments. These results are discussed in relation to the fitness cost of these genes and pattern of dispersal in C. pipiens.
\end{abstract}

Keyw ords: gene flow, mosquito, population structure, resistance genes.

\section{Introduction}

The mosquito Culex pipiens is one of the few insect species in which insecticide resistance, in particular to organophosphorous (OP) products, has been studied in the wild at the gene level (Raymond \& Pasteur, 1996). This mosquito is a vector of several diseases, and for this reason it has been the target of many control programmes worldwide. The widespread use of OP insecticides represents a powerful agent of selection in natural populations of the mosquito $C$. pipiens, in which three loci have developed several resistance alleles (Pasteur et al., 1981; Wirth et al., 1990; Poirié et al., 1992): Est-2, coding for esterase B, Est-3, coding for esterase A, and Ace, coding for acetylcholinesterase. At the Est-2 and Est-3 loci, several electromorphs with either a normal or high activity have been recorded, in addition to the null alleles (Mouchès et al., 1987; Poirié et al., 1992)

To date, four to six electromorphs with high activity for both A and B esterases have been described in C. pipiens, named A1, A2, A4, A5 and B1, B2, B4, B5, B6 and B7, according to the order of their discovery (Georghiou \& Pasteur, 1978; Pasteur et al., 1981; Raymond et al., 1989; Poirié et al., 1992;

*Correspondence. E-mail: severini@pop3.iss.it
Xu et al., 1994; Raymond \& Pasteur, 1996). The high activity of these esterases involved in OP resistance is caused by an enzyme overproduction. This overproduction is the result of gene amplification (Raymond et al., 1989; Poirié et al., 1992) and/or gene regulation (Rooker et al., 1996). The two loci are located on the same chromosome at less than $1 \%$ recombination, and in some situations, both esterase $A$ and $B$ loci are coamplified, which explains the tight statistical association of some electromorphs, like A2 and B2 (Rooker et al., 1996), A4 and B4, or A5 and B5 (Guillemaud et al., 1997). The sequences flanking the structural gene have always been coamplified with the gene and the 'amplicon' of B1 amplification from the Californian strain Tem-R was characterized by Mouchés et al. (1990).

Population studies suggest that the spread of resistance genes, such as overproduced esterase alleles, is largely governed by migration and selection (Raymond et al., 1989; Raymond \& Pasteur, 1996); mutations generating novel overproduced esterase alleles are probably quite uncommon and possibly unique events (Chevillon et al., 1995). In Italy, the control programmes against $C$. pipiens vary greatly, depending on local vector-control agencies and insecticide use (the OPs temephos and chlorpyrifos are the most used insecticides) (Severini et al., 1993, 1997). Recent surveys carried out across the 
whole country showed the presence of resistance alleles previously detected within the Mediterranean area: A1, A2-B2, A4-B4, A5-B5, C1 and $A c e^{R}$ (Severini et al., 1993, 1997). The A1 and A4-B4 esterases as well as the $A c e^{R}$ are present in the entire sampled area, although with marked heterogeneity in frequency between samples (mosaic distribution), whereas the presence of A2-B2, A5-B5 and $\mathrm{C} 1$ is restricted to a few areas (pocket distribution).

We performed a study on the population structure of $11 C$. pipiens field populations in order to assess the role of migration in resistance gene dispersal: gene flow between populations was studied by analysing the electrophoretic polymorphism of putative neutral genes in different geographical situations.

\section{Materials and methods}

\section{Mosquito samples}

Eleven C. pipiens samples were collected as larvae and/or pupae from April to August 1995 (Fig. 1). Identification of the species was by microscopic

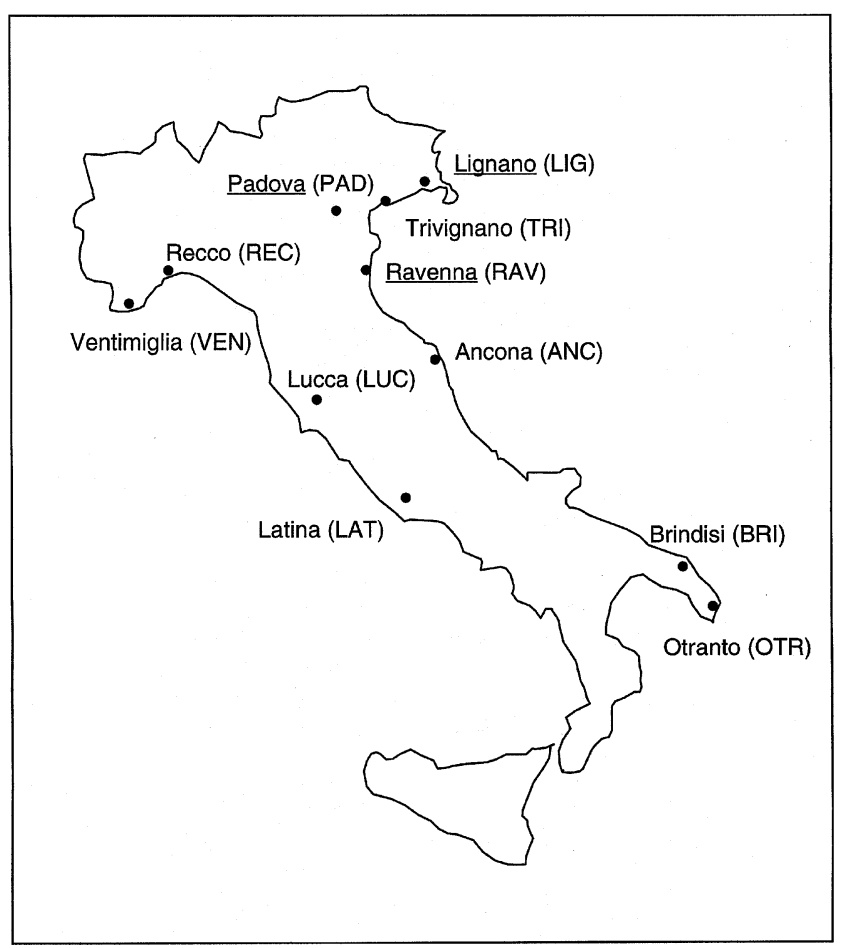

Fig. 1 Map of Italy showing the sites of collection of Culex pipiens. Population codes are in parentheses. Populations treated with OP insecticides are underlined. examination. Some of the larvae were immediately used for bioassay. The rest were reared under standard laboratory conditions until the imaginal stage, and 3-day-old adults were stored in liquid nitrogen for biochemical genetic investigation.

\section{Bioassays}

Bioassays were performed by exposing 25 early fourth instar field-collected larvae to various concentrations of insecticide (temephos or chlorpyriphos) in $200 \mathrm{~mL}$ volumes of dechlorinated tap water (World Health Organization, 1981). Control larvae were exposed to water alone. At least two replicates were run for each insecticide concentration according to the availability of the larvae. Bioassays were also carried out on ISS, a laboratory susceptible strain of C. pipiens (Villani et al., 1982). LC50 (the insecticide concentration inducing a mortality of $50 \%$ of the sample) was determined by log dosageprobit mortality regression analysis.

\section{Identification of known resistance genes}

Presence or absence of highly active esterases was determined on single mosquito homogenates by starch gel electrophoresis, as described in Pasteur et al. (1988). Several laboratory strains of known resistance were used as controls: esterase A1 strain BARRIOL (Pasteur et al., 1981), esterases A2-B2 strain SELAX (Wirth et al., 1990), esterases A4-B4 strain VIM (Poirié et al., 1992). Overproduced esterases A4-B4 and A5-B5, which show the same electrophoretic mobility under our experimental conditions, were discriminated by the RFLP (restriction fragment length polymorphism) pattern of the amplified region encompassing the esterase-B structural gene, using as control the strain CYPRUS homozygote for the presence of A5-B5 (Poirié et al., 1992). DNA was obtained as described in Raymond \& Marquine (1994), digested with the EcoRV restriction enzyme, run on agarose gel, transferred onto a nylon membrane, and hybridized with the $1.3 \mathrm{~kb}$ cDNA B1 probe of Mouchès et al. (1990), as described in Raymond et al. (1989).

Because of the dominance relationships between overproduced alleles and nonoverproduced ones, allelic frequencies cannot be computed in this case; instead, for each resistance allele (i.e. A1, A2-B2 or A4-B4), the proportion of mosquitoes displaying it is computed, and this proportion will be referred to here as 'frequency' for simplicity. Note that the sum of the 'frequencies' for each allele does not necessarily add up to one. 


\section{Genotype determination of neutral genes}

Electrophoretic studies were conducted on adult homogenates as described in Pasteur et al. (1988). For each mosquito it was possible to analyse up to 12 loci: $H b d h$ (hydroxybutyrate dehydrogenase, EC 1.1.1.30), $M d h-1$ and $M d h-2$ (two malate dehydrogenases, EC 1.1.1.37), $\mathrm{Me}-1$ and $\mathrm{Me}-2$ (two malic enzymes, EC 1.1.1.40), $I d h-1$ and $I d h-2$ (two isocitric dehydrogenases, EC 1.1.1.42), Aat-2 (aspartate aminotransferase, EC 2.6.1.1), Hk (hexokinase, EC 2.7.1.1), Mpi (mannose-6-phosphate isomerase, EC 5.3.1.8), Gpi (glucose-6-phosphate isomerase, EC 5.3.1.9) and Pgm (phosphoglucomutase, EC 5.4.2.2). The ISS strain was used as reference strain. The inheritance of these loci has been described previously (see Narang \& Seawright, 1982; Marshal, 1994), with the exception of $H b d h$.

\section{Statistics}

Population structure was analysed with the GENEPOP (version 2) software (Raymond \& Rousset, 1995). $F$-statistics were computed according to Weir \& Cockerham (1984). Heterozygote deficits or excesses were tested using an exact $U$-score test (Rousset \& Raymond, 1995). Genotypic associations between each pair of loci were tested for each population by a probability test as described by Raymond \& Rousset (1995), and over the whole data set by Ohta's variance analysis (Ohta, 1982), using the LINKDOs program (Garnier-Gere \& Dillman, 1992). Genotypic differentiation between populations was tested by computing an unbiased estimate of the $P$-value of a log-likelihood $(G)$ based exact test (Goudet et al., 1996). When necessary, the significance level of each test was adjusted by taking into account the other tests using the sequential Bonferroni method. The number of effective migrants $(\mathrm{Nm})$ was computed from $F_{\mathrm{ST}}$ estimates according to the equation $N m=\left(1 / F_{\mathrm{ST}}-1\right) / 4$ (Wright, 1969) and using the private allele method of Slatkin (1985). Isolation by distance was analysed as described by Rousset (1997), i.e. computing the relationship between pairwise estimates of $\hat{F}_{\mathrm{ST}} /\left(1-\hat{F}_{\mathrm{ST}}\right)$ and logarithms of geographical distance. A possible positive relationship was tested with the Mantel test, using the Spearman rank correlation coefficient as a statistic (as available in GENEPOP version 3.1). Geographical distances between samples were the shortest measurements on a map.

\section{Results}

\section{Insecticide resistance genes}

Bioassays were conducted on nine samples collected in Italy during the summer of 1995 . Three populations, Lignano, Padova and Ravenna, showed high levels of resistance (defined by the resistance ratio, $\mathrm{RR}$, relative to the susceptible ISS reference strain) for temephos, 200-, 133- and 153-fold, and chlorpyriphos, 67-, 186- and 183-fold, respectively, but the remaining populations were susceptible or, at most, showed low levels of resistance (Table 1). The observed levels of resistance were correlated with

Table 1 Resistance ratio and LC50 of temephos and chlorpyrifos and insecticide resistance gene distribution in Culex pipiens field populations from Italy. Frequency data of A1 from Padova and A5-B5 from Lignano are extracted, respectively, from Severini et al. $(1993,1997)$

\begin{tabular}{|c|c|c|c|c|c|c|c|c|c|c|c|c|c|}
\hline \multirow[b]{2}{*}{ Population } & \multirow{2}{*}{$\begin{array}{l}\text { Insecticide } \\
\text { treatment }\end{array}$} & \multicolumn{2}{|c|}{ Temephos } & \multicolumn{2}{|c|}{ Chlorpyriphos } & \multicolumn{4}{|c|}{ Esterases } & \multicolumn{4}{|c|}{ RFLP } \\
\hline & & LC50* & $\mathrm{RR}$ & LC50* & $\mathrm{RR}$ & $N$ & A1 & A2B2 & A4B4 & $N$ & B2 & B4 & B5 \\
\hline Lignano & Continuous & 0.03000 & 200 & 0.02900 & 67 & 60 & 0.15 & 0.03 & 0.90 & 57 & 0.04 & 0.07 & 0.51 \\
\hline Trivignano & Absent & 0.00300 & 20 & 0.00500 & 12 & 31 & 0.16 & & 0.90 & 20 & & 0.55 & \\
\hline Padova & Continuous & 0.02000 & 133 & 0.08000 & 186 & 86 & 0.30 & & 0.65 & 40 & & 0.56 & \\
\hline Recco & Absent & 0.00150 & 10 & 0.00170 & 4 & 31 & 0.19 & & 0.36 & 20 & & 0.35 & \\
\hline Ventimiglia & Absent & 0.00310 & 21 & 0.00160 & 4 & 45 & 0.07 & & 0.57 & 20 & & 0.38 & \\
\hline Ravenna & Continuous & 0.02295 & 153 & 0.07895 & 183 & 43 & 0.57 & 0.15 & 0.84 & 14 & 0.14 & 0.51 & \\
\hline Lucca & Absent & 0.00085 & 6 & 0.00620 & 14 & 58 & 0.21 & & 0.57 & 20 & & 0.33 & \\
\hline Ancona & Absent & 0.00018 & 1 & 0.00040 & 1 & 53 & 0.09 & & 0.81 & 30 & & 0.30 & \\
\hline Latina & Absent & 0.00040 & 3 & 0.00300 & 7 & 31 & 0.16 & & 0.55 & 26 & & 0.17 & \\
\hline Brindisi & Absent & 0.00240 & 16 & 0.00290 & 7 & 22 & 0.23 & & 0.64 & 25 & & 0.43 & \\
\hline ISS & & 0.00015 & & 0.00043 & & & & & & & & & \\
\hline
\end{tabular}

$* \mathrm{mg} / \mathrm{L}$.

$\mathrm{RR}$, resistance ratio relative to the ISS strain. 
the information regarding the presence or absence of organophosphate insecticide treatments (information on past history of treatments is given in Table 2). These results were also in agreement with previous results of Severini et al. (1993) for some of these populations.

Electrophoretic studies confirmed the presence of amplified esterases A1, A2-B2, A4-B4 (or A5-B5) as reported in previous studies (Bonning et al., 1991; Severini et al., 1993). The identity of esterase A1 was confirmed by the presence of the Est-2 $2^{0.64}-\mathrm{A} 1$ linkage disequilibrium found in all the samples studied. A1 and A4-B4 (or A5-B5) were present in all samples studied, although at different frequencies. In contrast, A2-B2 was observed in the sample from Lignano and Ravenna. Esterase A1 was at higher frequencies in populations where the resistance ratio was elevated, for both temephos and chlorpyriphos, whereas A4-B4 (or A5-B5) frequencies seemed to vary independently of the level of resistance (and hence with the presence of OP treatments), indicating differences in selection pressures. For the Lignano sample, which showed a high level of resistance, RFLP analysis of the amplified esterase B locus revealed a high frequency of A5-B5 esterases, which is known to confer a high level of OP resistance (Poirié et al., 1992). A5-B5 was not found in any sample other than Lignano.

\section{Neutral polymorphism genes}

A total of 485 mosquitoes were analysed for the 12 loci. In some cases, genotypes were not recorded for technical reasons. Overall, a total of 3443 genotypes were available for statistical analysis. The number of alleles detected varied between two (Mdh-1 and 2, Aat-2, Hk-2) and six (Pgm). For three loci, Mdh-2, $M e-1$ and $I d h-2$, the frequency of the most common allele was greater than $95 \%$ in all samples. Data concerning frequencies and $F_{\text {IS }}$ estimates of the most polymorphic loci relative to the Italian populations studied are available upon request.

Hardy-Weinberg equilibrium was rejected $(P<0.05)$ in three out of 65 tests, but none remained significant after applying the sequential Bonferroni test, indicating that the populations studied were substantially panmictic.

Gametic association was significant $(P<0.05)$ for only two out of 64 tests, and these associations concerned only two populations (Trivignano and Ravenna), which did not remain significant when the sequential Bonferroni test was applied. The linkage disequilibrium between two alleles of a pair of loci within a subdivided population is caused either by directional selection pressures or by genetic drift. To differentiate between random and selective causes of disequilibrium, Ohta (1982) devised a method for partitioning the variance of dilocus disequilibrium coefficients into within ( $D_{\mathrm{IS}}$ and $\left.D_{\mathrm{IS}}^{\prime}\right)$ and between $\left(D_{\mathrm{ST}}\right.$ and $\left.D_{\mathrm{ST}}^{\prime}\right)$ subpopulations components. The discrimination is based on the comparisons of $D_{\text {IS }}$ and $D_{\mathrm{ST}}$ values, on the one hand, and of $D_{\mathrm{IS}}^{\prime}$ and $D_{\text {ST }}^{\prime}$ values, on the other. For all pairs of loci studied, $D_{\mathrm{IS}}<D_{\mathrm{ST}}$ and $D_{\mathrm{IS}}^{\prime}>D_{\mathrm{ST}}^{\prime}$ and this observation was consistent with the hypothesis that the observed gametic associations were caused only by the action of drift, with the unique exception of the pair Hk-Mpi.

Although $F_{\mathrm{ST}}$ estimates were low for all loci, the overall differentiation among populations was highly significant $(P<0.0001)$ and corresponded to an $F_{\mathrm{ST}}$ estimate of 0.0096 , indicating a slight but significant genetic differentiation among the populations studied. Three loci out of 12, Aat-2, Mpi and Gpi, contributed mostly to genetic differentiation, showing significant $P$-values $(P<0.05) \quad$ (Table 3$)$. The importance of genetic exchanges among populations was assessed from the number of effective

Table 2 Information on insecticide treatments in the natural Culex pipiens populations analysed in the present study

\begin{tabular}{lc}
\hline Study populations & History of insecticide treatments \\
\hline $\begin{array}{l}\text { Ancona, Brindisi, Latina, Recco, } \\
\text { Trivignano, Ventimiglia }\end{array}$ & No treatments throughout the last 10 years \\
$\begin{array}{l}\text { Lignano } \\
\text { Intensively treated throughout the last } 20 \text { years; malathion and chlorpyriphos were } \\
\text { replaced by temephos in the early } 90 \text { s. Since } 1993 \text { the IGR diflubenzuron and } \\
\text { temephos were periodically alternated }\end{array}$ \\
$\begin{array}{l}\text { Intensively treated since } 1989 \text {; chlorpyriphos was replaced by temephos in } 1992 \\
\text { Intensively treated throughout the last } 15 \text { years; chlorpyriphos was replaced by } \\
\text { temephos in the early 90s } \\
\text { Lucca }\end{array}$ \\
$\begin{array}{c}\text { Intensively treated with chlorpyriphos until 1987; after that date only sporadic } \\
\text { treatments with temephos were performed }\end{array}$ \\
\hline
\end{tabular}


Table $3 F_{\mathrm{ST}}$ estimates and $P$-values and standard error $^{3}$ the test of differentiation (Goudet et al., 1996) for Culex pipiens field populations from Italy

\begin{tabular}{lrrr}
\hline Locus & \multicolumn{1}{c}{$F_{\text {ST }}$} & $P$ & \multicolumn{1}{c}{ SE } \\
\hline$M d h-1$ & 0.007 & 0.0858 & 0.0091 \\
$M d h-2$ & -0.004 & 1.0000 & $<0.0001$ \\
$M e-1$ & 0.003 & 0.0962 & 0.0061 \\
$M e-2$ & 0.006 & 0.1483 & 0.0090 \\
$I d h-1$ & -0.001 & 0.1351 & 0.0100 \\
$I d h-2$ & -0.001 & 0.7761 & 0.0113 \\
Aat -2 & 0.020 & 0.0087 & 0.0017 \\
$H k$ & 0.010 & 0.1161 & 0.0130 \\
Pgm & 0.004 & 0.0559 & 0.0130 \\
Hbdh & 0.007 & 0.1350 & 0.0157 \\
$M p i$ & 0.006 & 0.0044 & 0.0027 \\
$G p i$ & 0.019 & 0.0019 & 0.0014 \\
All & 0.009 & $<0.0001$ & \\
\hline
\end{tabular}

migrants, $N m$, computed from $F_{\mathrm{ST}}$ estimates of Weir \& Cockerham (1984) and with Slatkin's method based on private alleles; this was high $(\mathrm{Nm}>14)$, indicating that gene flow among Italian $C$. pipiens populations is extensive. There was a significant (Mantel test, 10000 permutations, $P=0.0013$ ) and positive relationship between $\hat{F}_{\mathrm{ST}} /\left(1-\hat{F}_{\mathrm{ST}}\right)$ and the logarithm of distance, indicating an isolation by distance at the scale studied (Fig. 2).

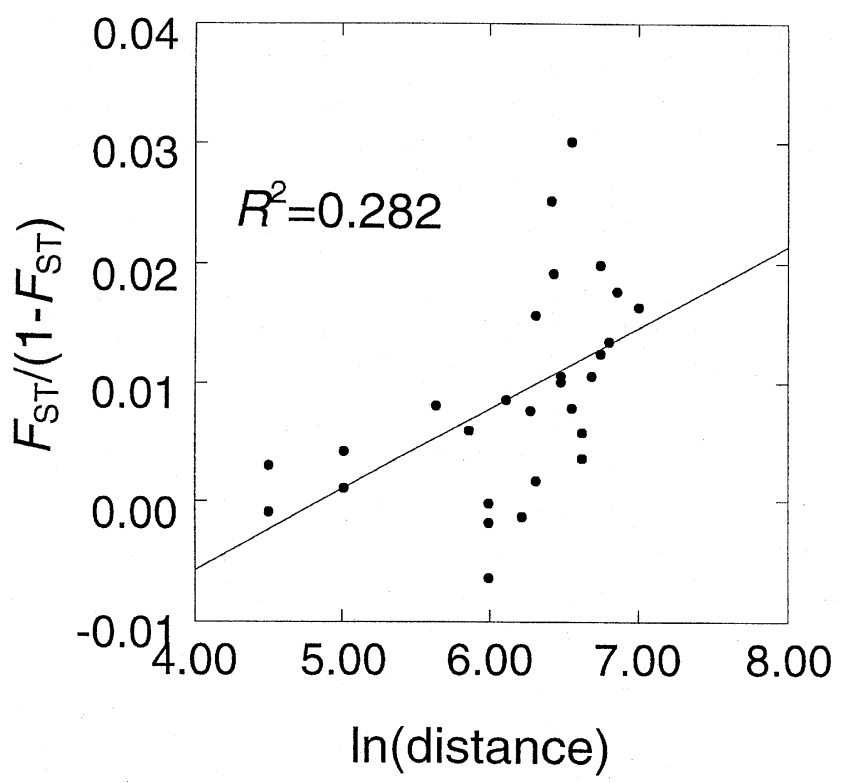

Fig. 2 Isolation by distance using the Rousset (1997) method. Pairwise estimates of $F_{\mathrm{ST}}$ were calculated according to Weir \& Cockerham (1984).

\section{Discussion}

The evolution of insecticide resistance provides a useful opportunity to study selection in natural populations. Previous studies on the evolution of resistance in field populations of $C$. pipiens have indicated that mutations transforming susceptible genes into resistance ones are extremely rare, indicating that the distribution of resistance genes is mainly the result of migration and selection (see, e.g. Guillemaud et al., 1996; Raymond \& Pasteur, 1996). For the latter, resistance genes are selected for in treated areas and apparently selected against in untreated areas, reflecting a pleiotropic cost. This cost seems allele-dependent in southern France (Chevillon et al., 1998), being different for distinct OP resistance genes, but the validity of this situation in other geographical areas is not known. The present study was undertaken to understand better the correlation between OP resistance genes and the genetic structure of field populations of $C$. pipiens in Italy.

For the distribution of the genetic variability, two distinct patterns occur, if we consider neutral genes (genes not influenced by the presence or absence of insecticide) and genes responsible for insecticide resistance. Statistical analyses of neutral genes confirm the hypothesis that gene flow between the populations studied is high, suggesting a strong influence of migration against the random effect of drift. The probable neutrality of the loci studied is supported by the absence of deviations from HardyWeinberg equilibrium and the lack of systematic selection on pairs of alleles at distinct loci. In addition, these results are consistent with the statistical independence of the loci studied and the concordant local differentiation and migrant estimates.

There was a significant isolation by distance in Italian C. pipiens populations (Fig. 2), which is at odds with results found in southern France (Chevillon et al., 1995). French data were analysed with Slatkin's method, where some points, corresponding to a low differentiation between some pairs of populations, are removed because of a negative $F_{\mathrm{ST}}$ estimate; in this situation, no $\mathrm{Nm}$ estimate could be computed. When the French data were re-analysed with the new method of Rousset (1997), a significant isolation by distance was found ( $\mathrm{F}$. Rousset, pers. comm.). Thus, it seems that at the scale of several hundred kilometres, there is isolation by distance in C. pipiens populations from southern Europe.

When insecticide resistance genes were considered, a strong differentiation was found, even between populations separated by short geographi-

(c) The Genetical Society of Great Britain, Heredity, 81, 342-348. 
cal distances. However, the distribution pattern of each gene was distinct and influenced by the presence of insecticide treatments. $\mathrm{A} 2-\mathrm{B} 2$ and A5-B5 were present only in the heavily treated Lignano sample, whereas A1 and A4-B4 showed a large heterogeneity among all samples.

The reason for the widespread distribution of the A4-B4 haplotype all over Italy must be explained. Apparently, this allele is easily maintained in field mosquito populations even without insecticide selection pressure, suggesting a low pleiotropic cost. This is in agreement with the situation of A4-B4 in Corsica (Raymond \& Marquine, 1994) or southern continental France (Chevillon et al., 1995). A4-B4 seems to increase in frequency in places where the treatments are performed with different insecticides (temephos in Corsica, temephos and chlorpyrifos in Italy, temephos, chlorpyrifos and fenitrothion in southern France). This hypothesis does not exclude a possible presence of residual doses of insecticides in untreated areas, possibly explaining the presence of this resistance allele in the whole of Italy.

The situation of A1 is similar that of A4-B4, except that A1 has a much lower frequency. This difference is unlikely to result from a difference in selection in the presence of insecticide, as the OP resistance provided by these two resistance alleles is similar (Poirié et al., 1992). Likewise, a difference in cost is suspected, with a higher cost for A1 than for A4-B4. This is consistent with results found in southern France (Chevillon et al., 1998). This situation, the older resistance gene (A1) being more costly than a more recent one (A4-B4), indicates that allele replacement - instead of selection of a cost modifier - takes place in the evolution of OP resistance for this mosquito.

The restricted distribution of resistance genes such as A2-B2 and A5-B5 suggests that either their introduction is recent or they are associated with a high pleiotropic cost in untreated areas. A2-B2 has already been detected in continental Italy, in a place where it has subsequently disappeared because of a change in insecticide usage. Its presence in Lignano probably indicates a new introduction in Italy, consistent with the propensity of this resistance gene to invade worldwide (Rivet et al., 1993; Guillemaud et al., 1996). A5-B5 has already been detected in Lignano (Severini et al., 1997), a place where OP treatments are continuous. It is remarkable to note that this resistance allele has not been detected in an untreated area only $100 \mathrm{~km}$ distant (Trivignano, Mestre). Considering the extensive gene flow detected by polymorphism of neutral genes, this situation indicates that A5-B5 is probably associated with a high pleiotropic cost.

The extensive gene flow between populations is not a limiting factor for the migration of resistance genes, except for long distances, as indicated by the significant isolation by distance for several hundred kilometres. The difference in the distribution of OP resistance genes seems to be the result of both the advantage they provide (A1 and A4-B4 have never been associated with high resistance, in contrast to A2-B2 or A5-B5) and the associated pleiotropic cost (A4-B4 has no cost or a reduced one compared to the other alleles).

\section{References}

BONNING, B. C., HEMINGWAY, J., ROMI, R. AND MAJORI, G. 1991. Interaction of insecticide resistance genes in field populations of Culex pipiens (Diptera: Culicidae) from Italy in response to changing insecticide selection pressure. Bull. ent. Res., 81, 5-10.

CHEVIllon, C., PASTEUR, N., MARQuine, M., Heyse, D. AND RAYMOND, M. 1995. Population structure and dynamics of selected genes in the mosquito Culex pipiens. Evolution, 49, 997-1007.

CheVillon, C., Bourguet, D., Rousset, F., PASteur, N. AND RAYMOND, M. 1998. Pleiotropy of adaptive changes in populations: comparisons among insecticide resistance genes in Culex pipiens. Genet. Res., 70, 195-204.

GARNIER-GERE, P. AND DILlMANN, C. 1992. A computer program for testing pairwise linkage disequilibrium in subdivided populations. J. Hered., 83, 239.

GEORGHIOU, G. P. AND PASTEUR, N. 1978. Electrophoretic esterase patterns in insecticide-resistant and susceptible mosquitoes. J. Econ. Entomol., 71, 201-205.

GOUDET, J., RAYMOND, M., DE MEEÜS, T. AND ROUSSET, F. 1996. Testing differentiation in diploid populations. Genetics, 144, 1933-1940.

GUILlEMAUD, T., ROOKER, S., PASTEUR, N. AND RAYMOND, M. 1996. Testing the unique amplification event and the worldwide migration hypothesis of insecticide resistance genes with sequence data. Heredity, 77, 535-543.

GUILlEMAUD, T., MAKATE, N., RAYMOND, M., HIRST, B. AND CALlaghan, A. 1997. Esterase gene amplification in Culex pipiens. Insect Mol. Biol., 6, 319-327.

MARShal, I. 1994. Cartographie de neuf gènes codant des enzymes chez Culex pipiens: Est-2, Est-3, Got-1, Got-2, Hk, Mdh-3, Mpi, Pgi et Pgm. Diplome d'Etude Approfondies 'Evolution et Ecologie', Université de Montpellier II, Montpellier, France.

MOUChÈs, C., MAGNin, M., BERGÉ, J. B., DE SILVESTRI, M., Beyssat, V., PASTEUR, N. AND GEORGHiOU, G. P. 1987. Overproduction of detoxifying esterases in organophosphate resistant Culex mosquitoes and their presence in other insects. Proc. Natl. Acad. Sci. U.S.A., 84, 2113-2116.

MOUCHÈs, C., PAMPlin, Y., AGARWAAL, M., LEMIEUX, L., Herzog, M., ABADOU, M. ETAL. 1990. Characterization 
of amplification core and esterase B1 gene responsible for insecticide resistance in Culex. Proc. Natl. Acad. Sci. U.S.A., 87, 2574-2578.

NARANG, S. AND SEAWRIGHT, J. A. 1982. Linkage relationships and genetic mapping in Culex and Anopheles. In: Steiner, W. W. M., Tabachnick, W. J., Rai, K. S. and Narang, S. (eds) Recent Developments in the Genetics of Insect Disease Vectors, pp. 231-272. Stipes Publishing Company, Champain IL.

OHTA, т. 1982. Linkage disequilibrium due to random genetic drift in finite populations. Proc. Natl. Acad. Sci. U.S.A., 79, 1940-1944.

PASTEUR, N., ISEKI, A. AND GEORGHIOU, G. P. 1981. Genetic and biochemical studies of the highly active esterases $\mathrm{A}^{\prime}$ and $\mathrm{B}$ associated with organophosphate resistance in the Culex pipiens complex. Biochem. Genet., 19, 909-919.

PASTEUR, N., PASTEUR, G., BONHOMME, F., CATAlAN, F. AND BRITTON-DAVIDIAN, J. 1988. Practical Isozyme Genetics. Ellis Horwod, Chichester.

POIRIÉ, M., RAYMOND, M. AND PASTEUR, N. 1992. Identification of two distinct amplifications of the esterase B locus in Culex pipiens L. mosquitoes from Mediterranean countries. Biochem. Genet., 30, 13-26.

RAYMOND, M. AND MARQUINE, M. 1994. Evolution of insecticide resistance in Culex pipiens populations: the Corsican paradox. J. Evol. Biol., , 7, 315-337.

RAYMOND, M. AND PASTEUR, N. 1996. Evolution of insecticide resistance in the mosquito Culex pipiens: the migration hypothesis of amplified esterase genes. In: Brown, T. M. (ed.) Molecular Genetics and Evolution of Pesticide Resistance, pp. 90-96. American Chemical Society, Washington, DC.

RAYMOND, M. AND ROUSSET, F. 1995. GENEPOP (version 1.2). Population genetics software for exact tests and ecumenicism. J. Hered., 86, 248-249.

RAYMOND, M., BEYSSAT-ARNOUTY, V., SIVASUBRAMANIAN, N., MOUChÉs, C., GEORGHIOU, G. P. AND PASTEUR, N. 1989. Diversity of the amplification of various esterases $\mathrm{B}$ responsible for organophosphate resistance in Culex mosquitoes. Biochem. Genet., 27, 417-423.

RIVET, Y., MARQUINE, M. AND RAYMOND, M. 1993. French mosquito populations invaded by A2-B2 esterases causing insecticide resistance. Biol. J. Linn. Soc., 49, $249-255$.

ROOKER, S., GUILlEMAND, T., BERGÉ, J., PASTEUR, N. AND RAYMOND, M. 1996. Coamplification of esterase A and $\mathrm{B}$ genes as a single unit in Culex pipiens mosquitoes. Heredity, 77, 555-561.

ROUSSET, F. 1997. Genetic differentiation and estimation of gene-flow from $F$-statistics under isolation by distance. Genetics, 145, 1219-1228.

ROUSSET, F. AND RAYMOND, M. 1995. Testing heterozygote excess and deficiency. Genetics, 140, 1413-1419.

SEVERINI, C., ROMI, R., MARINUCCI, M. AND RAYMOND, M. 1993. Mechanisms of insecticide resistance in field populations of Culex pipiens from Italy. J. Am. Mosquito Control Assoc., 9, 164-168.

SEVERINI, C., ROMI, R., MARINUCCI, M., GUILLEMAUD, T. AND RAYMOND, M. 1997. Esterases A5-B5 in organophosphate-resistant Culex pipiens from Italy. Med. Vet. Entomol., 11, 123-126.

SLATKIN, M. 1985. Rare alleles as indicators of gene flow. Evolution, 39, 53-65.

VILLANI, F., MAJORI, G. AND ROMI, R. 1982. Osservazioni preliminari sui livelli di sensibilità agli esteri fosforici in popolazioni italiane del complesso Culex pipiens. Parassitologia, 24, 245-253.

WEIR, B. S. AND COCKERHAM, C. C. 1984. Estimating $F$-statistics for the analysis of population structure. Evolution, 38, 1358-1370.

WIRTH, M., MARQUINE, M., GEORGHIOU, G. P. AND PASTEUR, N. 1990. Esterase A2 and B2 in Culex quinquefasciatus (Diptera: Culicidae): role in organophosphate resistance and linkage. J. Econ. Entomol., 27, 202-206.

WORLD HEALTH ORGANIZATION. 1981. Instructions for determining the susceptibility or resistance of mosquito larvae to insecticides. W.H.O./ VBC/ 81.807, Geneva.

Wright, s. 1969. Evolution and the Genetics of Populations, vol. 2, The Theory of Gene Frequencies. Chicago University Press, Chicago.

XU, J., QU, F. AND LIU, w. 1994. Diversity of amplified esterase B genes responsible for organophosphate resistance in Culex quinquefasciatus from China. J. Med. Coll. PLA, 9, 20-23. 